\title{
Opinion
}

\section{The Unsustainable City}

\section{Matthias Berger ${ }^{1,2}$}

1 Future Cities Laboratory, Singapore-ETH Centre, 1 CREATE Way, \#06-01 CREATE Tower, Singapore 138602, Singapore; E-Mail: mberger@arch.ethz.ch

2 Information Architecture, Department of Architecture, ETH Zurich, 8092 Zurich, Switzerland

Received: 28 October 2013; in revised form: 2 January 2014 / Accepted: 2 January 2014 /

Published: 13 January 2014

\begin{abstract}
Make cities more sustainable" is an omnipresent slogan in architecture and urban planning. This article is a discussion on theoretical and practical boundaries of using the expression "sustainability" with respect to the scientific community, therefore avoiding sustainability becoming a euphemism for "doing good". By definition, it can be concluded, cities developed as counterparts to the hinterland and, therefore, they axiomatically should be and are as a matter of fact unsustainable. Furthermore, sustainability is a binary, not a gradual concept. Something is either sustainable or not. Aiming to increase the sustainability is consequently a sham battle. It would be necessary to change our perception to acknowledge that cities should be unsustainable in order to become efficient, seen from a global perspective including the hinterland.
\end{abstract}

Keywords: cities; land-use; perception; sustainable development; unsustainability; urban planning

\section{Prelude}

"Make cities more sustainable" is an omnipresent slogan in architecture and urban planning. A quick Google image search reveals the utopian character of the term sustainable cities, as assembled in Figure 1. Thumbnail pictures in predominantly white, green, and blue colors celebrate the marriage of the bright and clean, even sterile urban envelope with nature, represented as a sufficient infusion of green spaces in the urban fabric; all together under a blue sky with some decorative clouds. Masdar City, "one of the most sustainable communities on the planet" is the most prominent realization of that fiction [1] —at least partially, since construction is ongoing. 
Figure 1. Green and blue are predominant colors in visions of future cities. The first four pages of Google image search results on "sustainable cities" from March 15 in 2013.

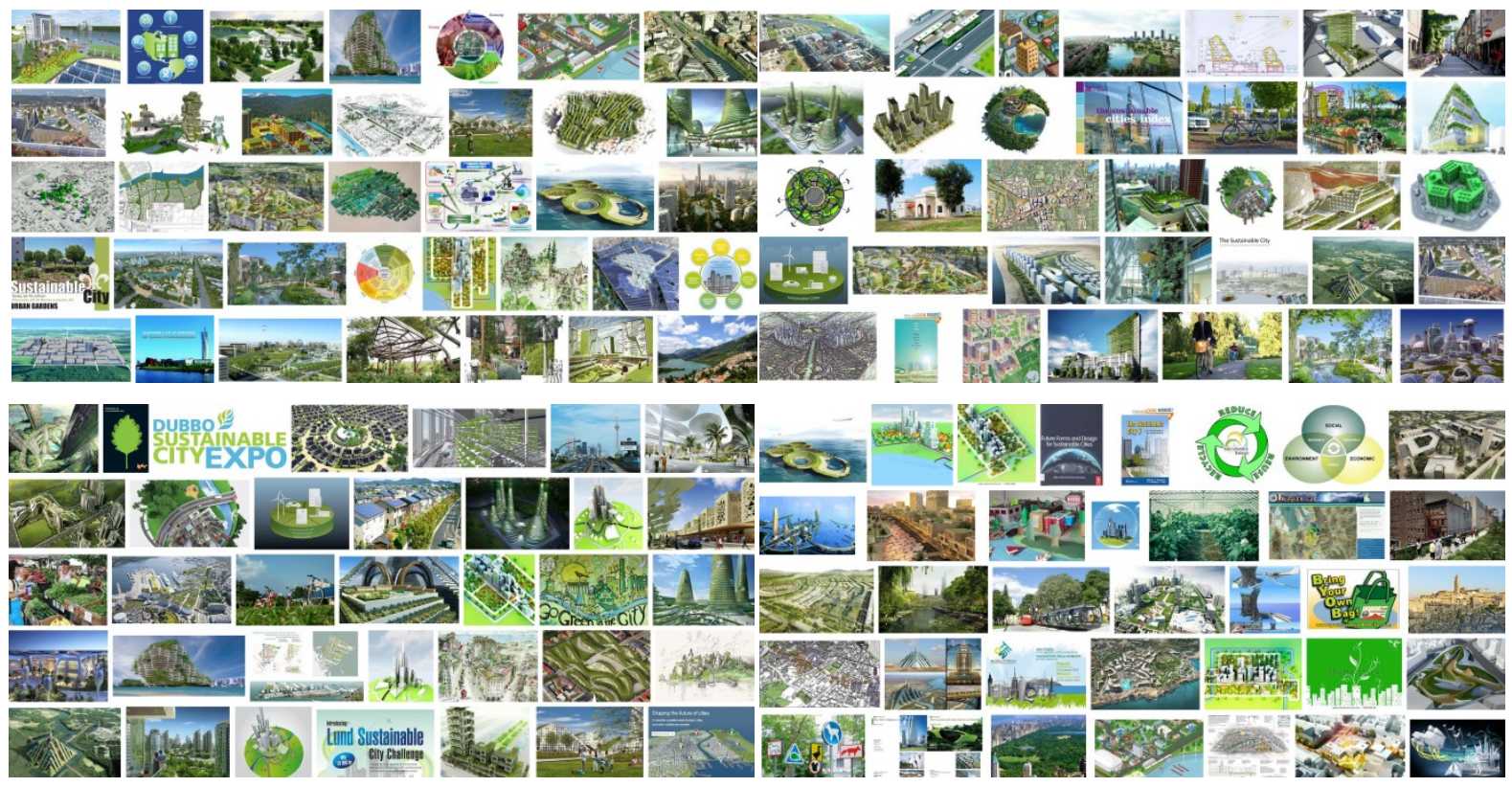

Again, I think, it is about time to evaluate the true meaning of sustainability, which should answer the question of what we need to do in order to make cities more sustainable. This article is therefore a discussion on theoretical and practical boundaries of using the expression sustainability with respect to the scientific community, avoiding that sustainability becomes a euphemism for "doing good". I will show that, by definition, cities are the counterparts to the hinterland, and thus they axiomatically should be and are unsustainable. Unsustainable cities have been studied for many decades, even from different perspectives, but almost entirely as an expression with negative connotation. When Dolores Hayden in 2012 revisits the famous 1939-1940 World's Fair the attention is put on human perception of futuristic scenarios and how this actually influences the trajectory of urban development [2]. Cars and their infrastructure are doomed as unsustainable by Hayden, and consequently cities, which are hosts for many cars and streets, entitled unsustainable cities. A more holistic view on urban networks in terms of city-hinterland dependencies and governmental failures is taken by Dentinho et al. [3], yet the case studies on islands (Easter Island, Santa Maria Island, and Corvo Island) fails to draw the link between the islands as geographic isolated places (by nature) and cities as functional concentrated places (by choice). Questioning the meaning of rural and urban as a matter of arbitrary boundaries, Allen exhibits a deeper recognition of what I will later call the "reference area" of sustainability, yet she understands sustainability as a complex of 5-dimensional interaction [4]. Scott Campbell is critical towards sustainable cites in [5], calling the conceptualization of sustainability "alluring", and describing "vague idealism", furthermore stating that a society as a whole is neither pure unsustainable nor should be fully sustainable, but in reality something in between. The fuzziness of sustainability's meaning is finally not dissolved by Campbell; he keeps the word and suggests adjusting its conceptualization. A key approach my article follows is beyond doubt Rees and Wackernagel's ecological footprint [6], maybe one of the strongest arguments for unsustainable cities in arguing that "no city or urban region can achieve sustainability on its own" [7]. Yet they use the word sustainability when talking about cities, 
where I argue that this is a categorical mismatch. Others topics on urban sustainability are typically measuring the sustainability [8], planning the sustainability [9], and broadening the meaning of sustainability [10], with the latter losing a close definition of urban sustainability to an extent that it becomes impractical for scientific usage.

\section{Introduction on Sustainability Today}

Even nowadays, the Brundtland report of 1987 is still mostly cited as "the" definition of sustainability [11]: "Sustainable development is development that meets the needs of the present without compromising the ability of future generations to meet their own needs". The temporal boundaries are future and present, yet future is not otherwise specified by a certain year or time span. Time is therefore a premise; we are looking into processes over time. When contextualizing sustainability with urban planning — and that problem is not limited to this specific field - the relation between subject and object of sustainability is mixed up, disconnected to the literal meaning of sustainability: something which is an object continuously exists in human presence, in analogy to the Cosmos in Plato's Timaeus [12].

The latter does indeed sound very static, and it might not fit to the idea of growth, progress, and change, as represented by cities. Many voices call for a more general view. Enabling sustainable cities requires an extension of the term sustainability to the six aspects of aesthetical, environmental, financial, functional, political, and social sustainability, it is said by Williams and Forbes [13], similar to Allen [4]. Suppose we extend the meaning as Williams and Forbes propose; we arrive at the point where sustainable future cities become visual fetish, hot topic and marketing target for mayors carrying the message "we care, don't worry" - care about what exactly? As I am going to show, the derivatives of sustainability discussed in the extended view neither address the correct subject nor do they help solve our environmental problems. First of all I would like to challenge the idea of the self-sufficient city, followed by tracing the roots of sustainability in order to find out what it was meant to be in the beginning. The key to understand why cities cannot be made more sustainable is described as a binary concept, concluding with a study of possible consequences in the ethical dimension.

\section{The Self-Sufficient City}

Urbanization is a process which seemingly shifts the human habitat from a widespread sparsely settled area into densified compounds, the so-called cities. Before, when man was hunting through the prairie, his habitat was as extended as his prey migrated. Now he lives in an air-conditioned condominium with minimal distance to the supermarket around the corner and comfortable commuting to work. It is a seemingly deceptive process, since our true habitat is still the entire planet Earth - a fact we are willing to admit when it comes to climate change and globalization. Cities bring everything closer together, and "[...] cities are where human beings have the lowest ecological footprint. It takes less energy, wood, material, and food to provide a good life for a person in a city than in the country", as often stated among urban planners in the USA, like Karlenzig and Marquardt [14]. In their ranking the authors list local food supply and renewable energy use among the criteria for sustainability, but admit to not taking into account the per capita consumption of energy and water and production of waste. The city is thereby understood as a metabolism, as exchange of stocks and flows, not as aggregation of 
individuals' behavior; yet embedded within something larger, alternatively either seen as hinterland, habitat, nation or planet Earth. Maintaining our habitat has been translated into the narrowed borders of self-sufficiency, and this is how self-sufficiency became a repeated key aspect for the sustainable city.

Let us start with a practical example. Singapore is well known for exporting urban solutions, such as testbed and research hub, and it is the venue where The Unsustainable City was written. The rhetoric of self-sufficiency as an integral part of survival "against all odds" [15] in this young nation is traditionally applied on the dependency on the resource water [16]; more recently, food [17] and energy were integrated. More details about Singapore's plans and visions can be found on sustainability [18], on the Singapore Green Plan 2012 [19] and watched [20]. In order to fulfill our current and future needs, urban habitats shall provide us with water, food, and energy instead of the simple service of shelter and protection. Especially for energy supply, wind and solar are considered as potential sources, assumed to be compatible with the urban built environment. Otherwise, unused roof and wall surfaces could contribute to a certain extent towards energy harvesting, since, for Singapore, an amount of 100 to $150 \mathrm{~km}^{2}$ is seen as feasible by the Solar Energy Research Institute of Singapore (SERIS). Note that the whole area of Singapore is only about $700 \mathrm{~km}^{2}$. Where this vision did came from? The success story of Germany's photovoltaics (PV) supported by feed-in tariffs, where on a nice sunny day half of the national electricity demand can be fueled by the sun, acts here as a driver for the whole solar idea, even in the tropics. Indeed, this is a huge gain for a potential sustainability. Only one thing does not fit in the comparison between Germany and Singapore: the nation, not individual cities, is the boundary for the evaluation of sustainability in terms of renewable energy supply. Individual German cities do not aim for self-sufficiency, because the "German Renewable Energy Act" is a nationwide attempt. Electricity can be transmitted over enormous distances with insignificant losses; therefore, no principal need for producing energy in cities or making them self-sufficient is deductible. Of course, nothing can be said against a double-usage of surfaces in cities, as long as no additional downside appears, which might be the case under tropical conditions due to an increase in anthropogenic heat production by PV installations. Outside of Singapore, assuming that land scarcity globally would require prioritization of land use, which is not unlikely keeping the estimated 9 to 10 billion humans in 2050 in mind, energy harvesting in cities could be an option. Yet we do not run out of deserts, and they qualify much better than cities for PV.

Cities in general are not self-sufficient when looking at the stocks and flows model. Food, water, waste, people, money, ideas, and much more passes through the city gates, since the gates are open and we are not dealing with medieval cities under siege. Cites compete on the globalized markets for talents, rich tax payers, and tourists. Why are certain parameters, e.g., energy, then declared to be a criterion for sustainability? Modern cities are by definition open systems, which exist by the exchange of goods, etc., and by interaction with other cities. Larger cities are more likely to have even more interaction. It is hard to understand where the obsession with a self-sufficient city, as displayed in Singapore, comes from. If we would encapsulate a city and inhibit any material flow with the world outside its boundaries "the city would cease to function and its inhabitants would perish within a few days", as Rees and Wackernagel wrote [7]. Going up the scale, from urban to rural to national to global, the reference area is not a problem for evaluating sustainability on the global scale, because Earth can be described as a closed system with energy exchange only to the outside. Mankind shares the whole Earth, so the sum of our consumption can be compared to the sum of what Earth offers. The other 
extreme is the individual, who can compare his or her consumption to the required area, an individual footprint. For the in-between scale, the urban to national, there is always the reference area and the system boundaries disputable. Some scholars, like the urbanist Peter Hall, suggest that the sustainable city is necessary on a global scale [21], in a way which would indicate a per-capita consumption criteria for sustainability. The location of these "capita" would in principle not matter (as McDonald and Patterson refer to the location and equivalence problem of the ecological footprint concept in [10] in terms of how sustainability can be comparative from case to case); hence, it does not contain the idea of city any more. Another ambiguity is Hall's entanglement of sustainability and exhaustible sources: "A sustainable city or metropolitan area is one that does not rob the earth of fixed, nonrenewable resources - or if it does, it does so at only a minimal decreasing rate" [21] is a logical contradiction to the meaning of sustinere.

Self-sufficiency on the urban or national scale and area, respectively, is not a matter of ecology or sustainability, but of a political and social dimension. It is very important in this line of arguments to understand that the object of sustainability is something material inside the reference area. Take an example: Scientists agree on the relevance of the Amazonian rainforest for the global climate, but to whom it belongs is vaguely defined. To the indigenous people living there, to São Paulo where they might move after they were expelled from their ancestor's land, to Brazil since they are also citizens, or to any human on earth breathing the air cleaned by the rainforest? That means, looking from the subject's perspective, we are considering individuals, citizens, cities, nations, or mankind. Of course we can apply the intertwined discourse of self-sufficiency and sustainability on a global scale, as the concepts of the ecological footprint or the carrying capacity do. The latter ask how many individuals of a species, in our case human, Earth can accommodate, whereas the first juxtaposes how many "Earths" we need to supply the humans. As a concept of practical application, sustainability has a surprisingly sharp focused background, which can help us today to change the use of sustainability in the context of cites. Now, let us have a look at the historical meaning first.

\section{Roots of Sustainability}

Sustainability's verbatim origin dates back further than commonly referenced from the USAperspective to the 1987 book Our Common Future [11]. In fact, it is a European invention and way of thinking. Ulrich Grober traces in his narrative journey sustainability back to Joachimsthal in Bohemia, now the town Jáchymov in the Czech Republic [22]. The silver mining business of the 16th century was a major source of income, but requiring large quantities of wood for shoring of mine tunnels and later for melting the ore. Two words originated from the mining business. The first is the dollar. The "Coin of Joachimsthal" was the "Joachimsthaler", which was colloquially abbreviated as German "Thaler" and later migrated to the English translation dollar. Secondly, and that is almost the opposite value than that which the dollar incorporates, the idea of sustainability. The forest required a management system to provide sufficient quantities of wood in the future. Many famous scholars got their experience and funding from joint research - to use the modern words - with the mining and forestry background [23]. The early method of practical sustainability is similar to accounting, by surveying the forests and indexing input and output. An early definition is given by Johann Heinrich Campe in his 
Dictionary of the German Language of 1809 "Nachhalt [sustain]: that which one holds on to when nothing else holds any longer" [24], as investigated by Siebenhühner [25].

Notable impact has been created by the 1972 book The Limits to Growth, which estimates growth potential under constrained resources [26]. The book has a similar tone to that of The Blue Marble, the famous picture by Apollo 17 from the same year. Both set the mixture of man and nature, the bluewhite-green, into a background of black: isolation, emptiness, finiteness. When the Google image search exemplifies the idea of sustainable cities as embedded into nature, the metaphor means safe in nature's bosom. As long as man fulfills the ideal of harmony, "Mother Nature" will care and everything is fine. The old pictures from the 70 s show an oppositional image, one of a fragile and tiny mother, somewhere lonesome in the universe. In summary, sustainability means responsible management of a renewable asset, so it may last into in(de)finite time, serving future generations (if $x$ is the asset at time $t$, than the equation (1) becomes a description of a sustainable asset if equation (2) at minimum which means that the asset stays constant over time). Growth of the asset is possible, but would not change the status from sustainable to something else.

$$
\begin{gathered}
x(t)=x(t-1)+\text { regeneration }- \text { depletion } \\
x=\text { constant } \text { or } d x / d t=0
\end{gathered}
$$

\section{A Binary Concept}

To pick the initial question up again, what can we do to make cities more sustainable? Many authors discussed the problem of lexical versus applied meaning of sustainability. Richard Shearman was the advocate of sustainability as a straight-forward concept of continuity through time, with no contextual dependencies [27]. The discourse about sustainable economic development led from the idea of a sustainable state to the idea of sustainable growth. Growth is the change of a state - so what is now the continuity through time? Given that the system Earth is limited, all processes within it must finally be limited in time and space as well. Unlimited growth is therefore impossible, so growth can hardly be a noun that fits to the adjective sustainable. The statements of political parties all over the world describe a specific growth target for their gross domestic product (GDP), mostly as a kind of natural or sustainable attribute of their economy. If something disturbs the constant growth pattern, it is irritating to the politicians. Singapore's Ministry of the Environment and Water Resources declares (see Sustainable Singapore [18]) that "Singapore can enjoy both economic growth and a good living environment for ourselves, and for future generations". Sustainable growth in this respect means the paradox of constant change, equation (3):

$$
d x / d t=\text { constant }
$$

Sustainability is essential a binary concept - meaning that either something is sustainable or it is not sustainable. If there is, for example, a forest as in Figure 2, in which there is a mean annual renewal B equal to the amount of logging $\mathrm{A}$, then this would represent the advent of sustainability. If less timber is taken from the forest, the system it is still sustainable, but not getting more sustainable. On the other hand, if say double the equal amount is logged the forest does not become half sustainable, it becomes unsustainable. A doubled logging rate of $2 \mathrm{~A}$ would reduce the stock and the renewal rate, so the stock 
would decline in future. Logging four times the equal amount (4A) would again not make the process less sustainable. Simply, the moment in future, when the stock is reduced to a certain extent would be sooner than in the case of the doubled logging rate. Sustainability is therefore not a gradual system.

Figure 2. Sustainability and unsustainability indicated as a function of logging versus regrowth and time on the left and as a time-dependent asset on the right.

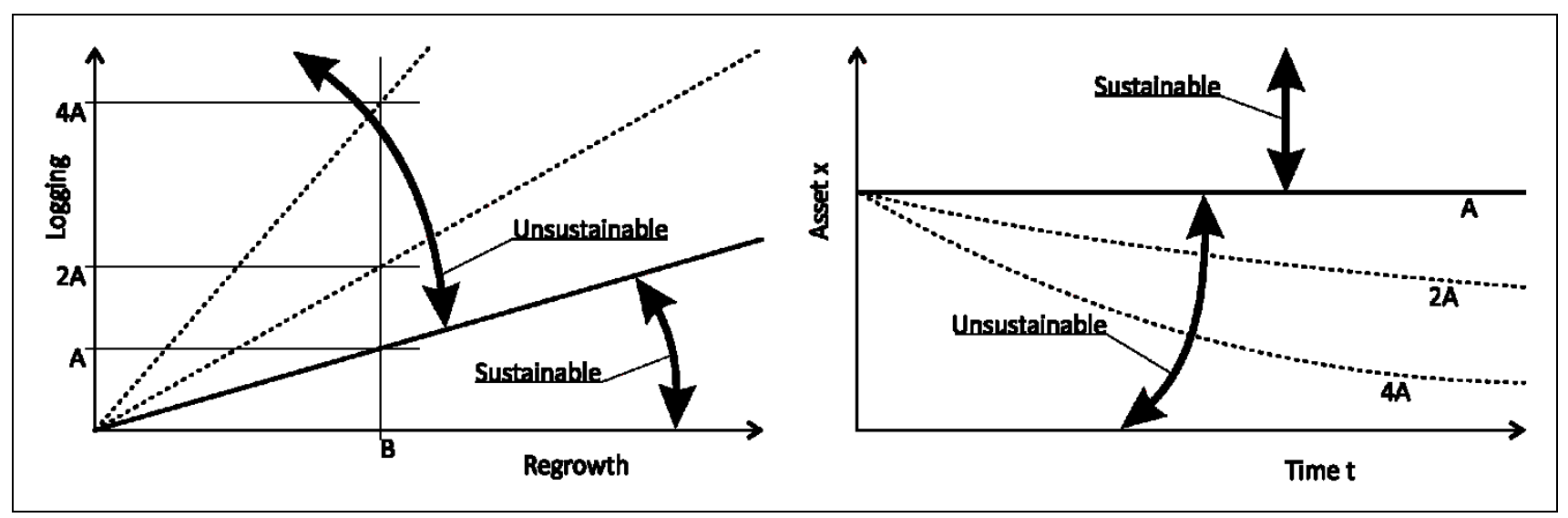

Sustainability as a measurement criterion which can only be applied on systems with a potential to renew, regenerate, or in general coming back to the stable point (equilibrium) where they started. The use of finite stocks of fossil fuels is a typical example for systems, where sustainability cannot be applied. Of course, economists like Elban S. Goodstein would reject this view by applying neoclassical sustainability, where they assume created capital can substitute natural resources [28]. However, if, e.g., oil should be kept for the needs of future generations, then nothing could be consumed at all, neither now, nor in future.

If we relax the meaning of sustainability to include financial or social aspects, would there be any logical flaw in the idea of sustainability as a binary concept? Usually, cities run up a huge debt, which would indicate unsustainability, and in the case of Singapore the opposite would have to be true. Governmental holdings like Temasek manage the surplus of the city state, and since surplus is generated perpetually the consequence would be to declare Singapore as financially sustainable. Capital would furthermore be a quantity which can act as a measure for a gradual sustainability - huge debt, little debt, moderate earnings, etc. However, is it still sustainability we are talking about or simply financial matter like balance and liquidity? Sustained growth might be a strategy, a sustained balance desirable, but all of that has nothing to do with sustainability. Surely: sustainability cannot be measured by the net national welfare (Net national welfare $(\mathrm{NNW})=$ total output - costs of growth - depreciation $=$ GDP + nonmarket outputs - externality costs - pollution abatement and cleanup costs - depreciation of created capital - depreciation of natural capital), as Goldstein writes [28], converting physical assets into monetary equivalents.

\section{The Ethical Dimension}

Next to the syntax of subject and object in sustainability, the technical analysis on reference areas, growth and boundaries, there is doubtless an ethical dimension in sustainability, coming with its own history. In his modification of Kant's Categorical Imperative Hans Jonas developed The Imperative of 
Responsibility [29], establishing a modern definition of sustainability some eight years before the Brundtland report [11]; Jonas suggested: "Act so that the effects of your action are compatible with the permanence of genuine human life". His work is much more known and integrated within the Germanspeaking countries and contributed even to "Article 11" of "The Treaty on the Functioning of the European Union" [30]: "Environmental protection requirements must be integrated into the definition and implementation of the Union's policies and activities, in particular with a view to promoting sustainable development". Notably, this article received an even higher priority in the treaty than consumer protection and free trade [31]. Sustainability can be understood as ecological responsibility, as illustrated already [32]. For the leading representative of recent utilitarianism, Australian philosopher Peter Singer, who, in particular, acknowledges other species' rights, sustainability on a global scale becomes a cooperation of man and nature. In contrast, sustainability in economics seems to follow only the biblical doctrine of dominium terrae, the cultural mandate of Genesis 1:28 [33]. Unfortunately, no limit has been placed, when this task should end in terms of population growth or cultivation of land. Sustainability, even by Jonas' definition, offers no guidance in finding upper limits of growth either. Permanence of human life, like in the dystopian future world of the movie The Terminator, where mankind is on the edge of extinction, is possible even though it would have a different quality. Sustainability is not arguing about qualitative aspects of human life, but is it closely connected to it? If we include other species' rights, if we would keep parts of Earth unexploited or untouched, the answer would be yes. It is currently no, if Malthusian growth in population and consumption continuous to be the main strategy in world's competing economies.

\section{Conclusion}

Sustainability in public perception is pointing to today's cities, stating that their condition is somehow bad, and hence, urbanization is ongoing. "Today's cities are not sustainable, yet we need not abandon urban centers and return to rural living. In short, we must have cities" [34]. "The Unsustainable City" is not meant to be an apocalyptic or resigned view but rather a reframing of the question how we can make cities better. A normative approach would focus on defining standards of livability, environmental impact, and economic prospect in and of a city. Those standards are interdependent of time and location, set by a society as plans for a change the city needs to undergo to make it better, or at least to preserve human achievements. If, for example, a city in a desert creates a huge impact due to cooling needs and long transport routes for food and consumer goods, then a more appropriate climate might better host the inhabitants on a different location. Yet both locations, desert and, in the best case the Garden of Eden, could exist and be totally sustainable, if the necessary supply (or reference) area in both cases would be given without compromising others in time and space. "[Cities] are not by themselves sustainable" [7], and I believe they are the very idea of unsustainability, built in contradiction to nature, unlike rural living within nature. Finally, sustainability cannot address the problems associated with growth; it can only indicate how we manage the consumption of renewable goods.

\section{Conflicts of Interest}

The authors declare no conflict of interest. 


\section{References}

1. Masdar city. Available online: http://masdarcity.ae/en/ (accessed on 8 January 2014).

2. Hayden, D. "I have seen the future" selling the unsustainable city. J. Urban History 2012, 38, 3-15.

3. Dentinho, T.P.; Gil, F.S.; Silveira, P. Unsustainable cities, a tragedy of urban networks. CS-BIGS 2011, 4, 101-107.

4. Allen, A. Sustainable cities or sustainable urbanisation? Available online: http://www.ucl.ac.uk/ sustainable-cities/results/gcsc-reports/allen.pdf (accessed on 2 January 2014).

5. Campbell, S. Green cities, growing cities, just cities? Urban planning and the contradictions of sustainable development. J. Am. Plann. Assoc. 1996, 62, 296-312.

6. Wackernagel, M.; Rees, W. Our Ecological Footprint: Reducing Human Impact on the Earth; New Society Publishers: Gabriola Island, Canada, 1962; p. 160.

7. Rees, W.; Wackernagel, M. Urban ecological footprints: Why cities cannot be sustainable — and why they are a key to sustainability. Manag. Urban Sustain. 1996, 16, 223-248.

8. Alberti, M. Measuring urban sustainability. Environ. Impact Assess. Rev. 1996, 16, 381-424.

9. Fistola, R. The unsustainable city. Urban entropy and social capital: The needing of a new urban planning. Procedia Eng. 2011, 21, 976-984.

10. McDonald, G.W.; Patterson, M.G. Bridging the divide in urban sustainability: From human exemptionalism to the new ecological paradigm. Urban Ecosyst. 2007, 10, 169-192.

11. Brundtland, G.H. Our Common Future; Oxford University Press: Oxford, UK, 1987; Volume 383.

12. Tufts University Perseus Digital Library. Available online: http://www.perseus.tufts.edu (accessed on 8 January 2014).

13. Williams, J.; Forbes, W. Toward a More Livable World: Social Dimensions of Sustainability. Stephen, F., Ed.; Austin State University Press: Nacogdoches, TX, USA, 2012.

14 Karlenzig, W.; Marquardt, F. How Green is Your City? The Sustainlane US City Rankings; New Society Publishers: New York, NY, USA, 2007.

15. Josey, A. Lee Kuan Yew: The Critical Years: 1971-1978 (Vol. 2); Marshall Cavendish International Asia Pte Ltd.: Singapore, Singapore, 2013.

16. Sung, T.T. Water Resources Planning and Development Singapore. In Water Resources, Environment, and National Development: Proceedings; Science Council of Singapore: Singapore, Singapore, 1972; p. 17.

17. Lim, K.C. Fresh food supplies in singapore. Geo. J. 1982, 4, 61-72.

18. Sustainable Singapore. Available online: www.sustainablesingapore.gov.sg (accessed on 8 January 2014).

19. Ministry of the Environment and Water Resources. Available online: www.mewr.gov.sg/sgp2012 (accessed on 8 January 2014).

20. First Commercial Vertical Farm opens in Singapore. Available online: http://www.archdaily.com/ 291403/first-commercial-vertical-farm-opens-in-singapore/ (accessed on 8 January 2014).

21. Piedmont-Palladino, S.; Mennel, T. Green community. Available online: http://www.nbm.org/ exhibitions-collections/exhibitions/green-community/green-community.html (accessed on 7 January 2014).

22. Grober, U. Sustainability: A Cultural History. Green Books: Devon, UK, 2012; p. 224. 
23. Von Goethe, J.W. Italian Journey (1786-1788); Suhrkamp: New York, NY, USA, 1989.

24. Campe, J.H.; Soltau, D.W.; Schönberger, F.X. Wörterbuch der deutschen Sprache (in German). Erscheinungsort: Braunschweig, Germany, 1809.

25. Siebenhüner, B. Homo Sustinens-Auf dem Weg zu einem Menschenbild der Nachhaltigkeit (in German); Metropolis-Verlag: Marburg, Germany, 2001.

26. Meadows, D.H.; Meadows, D.L.; Randers, J.; Behrens, W.W. The Limits to Growth-A Report to the Club of Rome; Universe Books: New York, NY, USA, 1972; Volume 22.

27. Shearman, R. The meaning and ethics of sustainability. Environ. Manage. 1990, 14, 1-8.

28. Goodstein, E.S. Economics and the Environment, 6th ed.; Wiley: Hoboken, NJ, USA, 2010; p. 558.

29. Jonas, H. Das Prinzip Verantwortung: Versuch einer Ethik fur die Technologische Zivilisation (in German); Insel-Verlag: Frankfurt am Main, Germany, 1979; p. 423.

30. The treaty on the functioning of the European Union. Available online: http:/eur-lex.europa.eu/ LexUriServ/LexUriServ.do?uri=OJ:C:2008:115:0047:0199:en:PDF (accessed on 9 January 2014).

31. Cullen, R. Green Taxation in East Asia; Edward Elgar Publishing: Hong Kong, China, 2011.

32. Berger, M. Path Creation-The Case of Singapore. In Proceedings of 35th IAEE International Conference, Perth, Austrilia, 2012.

33. The First Book of Moses, called Genesis. Available online: http://faithofgod.net/tanak/ge.htm (accessed on 9 January 2014).

34. Eisen, J.B. Toward a sustainable urbanism: Lessons from federal regulation of urban stormwater runoff. WULS 1995, 48, 1.

(C) 2014 by the authors; licensee MDPI, Basel, Switzerland. This article is an open access article distributed under the terms and conditions of the Creative Commons Attribution license (http://creativecommons.org/licenses/by/3.0/). 